\title{
Direitos na loucura: o que dizem usuários e gestores dos Centros de Atenção Psicossocial (CAPS)
}

Bruno Ferrari Emerich(a)

Rosana Onocko Campos(b)

Eduardo Passos ${ }^{(\mathrm{c})}$

Emerich BF, Campos RO, Passos E. Rights within madness: what psychosocial care center users and managers say. Interface (Botucatu). 2014; 18(51):685-96.

Through questioning the concept of autonomy and the interface with exercising of rights, this paper aim to identify and comprehend the concept of the rights of psychosocial care center users, from the opinions of these users and those of managers of these services. This was a fourth-generation multicenter qualitative study in which material was gathered from focus groups and interviews, by means of audio recordings that were transformed into narratives. Interpretation of the data indicated that exercising of rights is achievable through the emergence of legal subjects. Through analyzing the relationships between these players, modulated by biopower, it could be seen that a circuit was formed, in which users were included. In the open, total practices produced means of control over users and over their exercising of rights, which might generate chronicity among users, workers, managers and services.

Keywords: Mental health. Autonomy. Human rights. Psychiatry. Qualitative research.
Por meio da problematização do conceito de autonomia e da interface com o exercício de direitos, este artigo pretende identificar e compreender a concepção de direitos dos usuários de CAPS, a partir das vozes deles e dos gestores destes serviços. Trata-se de uma pesquisa multicêntrica qualitativa de quarta geração, cujo material foi levantado em grupos focais e entrevistas, áudio gravados e transformados em narrativas. A compreensão dos dados indica que o exercício dos direitos torna-se possível pela emergência de sujeitos de direitos. Analisando as relações entre estes atores, moduladas pelo biopoder, foi possível apreender a formação de um circuito no qual os usuários são inseridos. A céu aberto, práticas totais produzem formas de controle sobre usuários e sobre o exercício de direitos por parte destes, o que pode gerar cronicidade dos usuários, dos trabalhadores, dos serviços e dos gestores.

Palavras-chave: Saúde Mental. Autonomia. Direitos Humanos. Psiquiatria. Pesquisa qualitativa.

\footnotetext{
(a,b) Departamento de Saúde Coletiva, Faculdade de Ciências Médicas, Universidade Estadual de Campinas. Rua Tessália Vieira de Camargo, 126, Cidade Universitária. Campinas, SP, Brasil. 13.083-887. brunoemerich@ yahoo.com.br; rosanaoc@mpc.com.br (c) Instituto de Psicologia, Universidade Federal Fluminense. Niterói, RJ,Brasil.e.passos@ superig.com.br
} 


\section{Introdução}

O direito dos usuários em intenso sofrimento psíquico destacou-se como temática deste trabalho a partir do seu silêncio, seja na literatura científica, seja na fala dos participantes de uma pesquisa em saúde mental que aqui discutiremos. Acreditamos que esse direito é fundamental para a construção de novas formas de cuidado aos usuários e para a consequente reestruturação de serviços e ações.

A pesquisa GAM (Gestão Autônoma da Medicação) ${ }^{1}$ tematizou o uso da medicação psiquiátrica e problematizou formas de negociação desta por parte do usuário, o que trouxe barulho a um silêncio: o poder sobre a medicação, frequentemente concentrado nos profissionais, e a exclusão da voz dos usuários no processo de escolha e negociação dos psicofármacos. Percebemos que o conhecimento acerca dos direitos dos usuários, que deveria ser um pressuposto básico aos trabalhadores e gestores, era desconhecido por estes.

Num país em que a precariedade de acesso a direitos sociais para sobrevivência é cotidiana, o usuário em intenso sofrimento psíquico parece, muitas vezes, experimentar um duplo processo de exclusão: ser brasileiro e louco. Como grande parte da população, tem direitos sociais básicos desrespeitados. Por experimentar formas de relação com o mundo e com o outro que contrastam com os códigos socialmente estabelecidos, muitas vezes, sequer tem acesso à informação sobre seus direitos.

Este artigo tem por objetivo analisar a perspectiva de usuários e gestores de CAPS acerca dos direitos dos usuários de CAPS, construindo interpretações possíveis para as aproximações e distanciamentos das diferentes vozes.

\section{CAPS: sobre autonomia, poder e cogestão}

Os CAPS têm se consolidado como referência ao tratamento em saúde mental ${ }^{2}$, responsabilizando-se por promover assistência ampliada aos casos de usuários em intenso sofrimento psíquico, a partir de ofertas de cuidado clínico singularizado aos usuários, por meio de diferentes ações.

Diferentemente de instituições totais ${ }^{(d) 3}$ que operam na lógica da segregação produzindo, no caso das instituições em saúde mental, a perda da identidade e redução dos sujeitos à doença mental - entendida como desvio social ou moral -, os CAPS propõem cuidados a partir da clínica ampliada ${ }^{4}$. A ampliação da prática de cuidado pressupõe a valorização da subjetividade, singular e complexa, e a possibilidade de trocas cotidianas nos planos micro e macropolítico, considerando as dimensões sociocultural e jurídico-política da Reforma Psiquiátrica Brasileira ${ }^{5}$. "Entre" sujeitos e instituições, "entre" clínica e política devem ser problematizados os direitos dos usuários em intenso sofrimento psíquico.

Onocko Campos e Campos ${ }^{6}$ indicam que o processo de construção de autonomia dá-se no movimento de coconstrução de sujeitos e coletivos. Desse modo, podemos pensar que a autonomia pode ser atingida em maiores ou menores graus durante momentos da vida. Ao aumentar o poder de agir sobre si e sobre o contexto onde vive, é possível aumentar a rede de dependência (pessoas, lugares, instituições), desenvolvendo redes de apoio nas quais se tornam possíveis maiores graus de autonomia.

A construção de autonomia não se reduz à explicitação de diferenças e construção de consensos. Implica negociação de saberes e valorização da visão e experiência dos usuários e de sua rede de apoio. Tais negociações são, intermitentemente, atravessadas por relações de poder.

\footnotetext{
(d) Goffman classifica o Hospital Psiquiátrico como um dos tipos de Instituição Total, onde os internos permanecem longo tempo separados do mundo externo, tendo controladas suas necessidades a partir da organização institucional. São constantes os processos de "mortificação do eu", com consequente perda da identidade dos internados.
} 
Oliveira e Passos ${ }^{7}$ problematizam as novas formas de subjetivação da sociedade contemporânea que, segundo Foucault, são caracterizadas pelo biopoder, que regulamenta e massifica os processos de vida não mais capturando o corpo individuado do vivo, mas, sim, a dimensão pulsional do viver.

O poder no capitalismo contemporâneo menos reprime do que molda e modula a vida, produzindo existências assujeitadas por normas disciplinares e práticas de regulamentação da vida. Essas relações de poder incidem sobre quem está no centro da organização social, mas, também, sobre quem está na sua periferia, como pessoas que recebem algum diagnóstico psiquiátrico.

Tomando a relação entre saúde mental e modulações de poder, é possível problematizar os diferentes espaços pelos quais circulou e circula a loucura ${ }^{5}$. No Brasil, no final do século XX, serviços de saúde territoriais passam a articular uma complexa rede de cuidados ao usuário em intenso sofrimento psíquico. Equipamentos substitutivos que operam alteração na lógica de cuidados, e não apenas num local circunscrito de cuidados, mesmo que alguns insistam em nomear tais equipamentos como alternativos.

As práticas do biopoder não substituíram, definitivamente, aquelas do poder disciplinar. Convivemos, no contemporâneo, com instituições disciplinares remanescentes das estratégias de poder do capitalismo do século XVIII e com biopolíticas que se exercem a céu aberto. Nesse sentido, ainda devemos manter, como agenda clínico-política, o combate às práticas de uma anatomopolítica de docilização de corpos, ainda utilizadas com os usuários da saúde mental.

O controle proveniente do biopoder, tão típico da sociedade atual, nos obriga a uma atenção às novas formas de assujeitamento que podem prescindir dos muros das instituições totais. No entanto, importa afirmar que, malgrado os perigos contemporâneos da regulamentação biopolítica da vida, o fato de caírem os muros dos hospícios faz avançar o movimento da reforma psiquiátrica brasileira na direção de novas formas de cuidados aos usuários e da democratização institucional no campo da saúde mental.

Apontamos isto porque não é incomum ouvir que criamos o "CAPScômio" ou que "está acontecendo uma capscização" da rede de saúde mental. Consideramos que cuidar do sujeito em seu território, com direito à circulação por diferentes espaços (físicos e simbólicos), qualifica o tratamento. O hospital psiquiátrico tira o que nos torna humanos: a singularidade e a liberdade.

A mudança na lógica de cuidados traz consigo novos riscos e aprisionamentos a serem continuamente analisados. Em formas de tratamentos "não manicomiais", a prática do controle pode se mascarar: a medicação pode tornar-se um meio de vigilância e tamponamento de sintomas, sendo pouco discutida e negociada com o usuário; as visitas domiciliares podem tornar-se monitoramento.

Ou seja, práticas e encontros que teriam potência para fortalecer a autonomia dos usuários podem ser tentáculos que promovem sua captura. O circuito, denunciado por Goffman ${ }^{3}$, deixa de circunscrever-se a instituições totais, passando a operar no que chamamos de Práticas Totais, conforme veremos mais adiante.

\section{Direitos e loucura: o que tem sido produzido no Brasil}

Ainda há poucas publicações acerca da temática dos direitos dos ditos loucos. Podemos citar, como marcos fundantes, a Lei $10216^{8}$ e a "Carta de direitos e deveres dos usuários e familiares dos serviços de saúde mental" 9 .

Sem desconsiderar a importância da bibliografia acerca do tema, destacamos aqui algumas produções que têm como pressuposto a participação protagonista dos usuários.

Vasconcelos ${ }^{9}$ tem trabalhado o conceito de empoderamento como importante para a construção de relações mais democráticas, que tenham o direito como premissa, o que inclui o protagonismo de usuários em iniciativas como o Grupo de Ajuda Mútua e o Grupo de Ajuda Compartilhada.

Em pesquisas avaliativas em saúde mental, Onocko Campos et al. ${ }^{10}$ incluem usuários como protagonistas na produção de conhecimento e práticas em saúde mental. Considerar que o sujeito possa narrar sua história e investir na formulação e execução de novos arranjos de cuidado passa a ser uma diferente postura em relação a direitos.

O Cartão e Plano de Crise ${ }^{11}$ são instrumentos em que os usuários podem ter seus direitos e interesses respeitados quando são necessárias intervenções em momentos de crise. Construídos pelos 
usuários junto à equipe que os atende, estes instrumentos contêm informações acerca da melhor forma de atenção ao usuário em crise, permitindo a distribuição do poder sobre a ação e avaliação em saúde mental, valorizando a experiência do sujeito e o saber do usuário.

Outra experiência de garantia de direitos assinada por usuários é o "Guia do Usuário da Saúde Mental", proposto pela AFLORE (Associação Florescendo a Vida - Campinas), que apresenta recursos importantes para o tratamento em dispositivos grupais" ${ }^{12}$. Na mesma direção, o "Guia de direitos: loucura cidadã" foi produzido por usuários e familiares da Associação Metamorfose Ambulante ${ }^{13}$.

A interface saúde mental/direito deve ser considerada nas diferentes dimensões da Reforma Psiquiátrica ${ }^{14}$. É necessário considerar o usuário dos serviços de saúde mental como protagonista e cogestor de sua vida, o que altera o modo de pensar a doença mental (dimensão epistemológica). Por outro lado, a Reforma se assenta em dispositivos legais de defesa dos direitos e cidadania, conduzindo a um processo de recomposição inclusiva do tecido social (dimensão jurídico-política), garantindo acesso a cuidados em serviços territoriais (dimensão técnico-assistencial), por meio da inscrição social e convivência (dimensão sociocultural).

\section{Metodologia: pesquisa e análise}

Os conteúdos analisados neste artigo são resultantes da "Pesquisa avaliativa de saúde mental: instrumentos para a qualificação da utilização de psicofármacos e formação de recursos humanos GAM-BR"1, que teve por objetivo traduzir, adaptar e testar, em CAPS do Rio de Janeiro (RJ), Novo Hamburgo (RS) e Campinas (SP), o "Guia Gestão Autônoma da Medicação" (GGAM) em pacientes com transtornos mentais graves. Originada no movimento comunitário de Quebec, a estratégia GAM teve início na década de 1980 como uma abordagem em que o usuário está no centro das decisões de seu tratamento medicamentoso ${ }^{15}$. Dentre os diferentes aspectos abordados no GGAM, destaca-se a discussão dos direitos

A pesquisa foi desenvolvida por quatro Universidades brasileiras: Universidade Estadual de Campinas (SP), Universidade Federal Fluminense (RJ), Universidade Federal do Rio de Janeiro (RJ) e Universidade Federal do Rio Grande do Sul (RS), a partir de um convênio firmado com a Aliança Internacional de Pesquisa entre Universidade e Comunidade (ARUCI/IDRC) ${ }^{15}$.

O caráter qualitativo do estudo parte do pressuposto da intersubjetividade (as relações humanas afetam a produção de conhecimentos), e do entendimento de que as realidades sociais são significativas e ocorrem a partir de contextos construídos socialmente ${ }^{16}$. Assim, o pesquisador é visto como participante dos processos sociais e reconhecido como mais um ator social, valorizando os sujeitos e entendendo que existe um vínculo intermitente entre o mundo externo e a vivência subjetiva.

A pesquisa avaliativa de quarta geração ${ }^{17}$ propicia a inclusão de diferentes pontos de vista e valores dos grupos de interesse envolvidos ${ }^{18}$. Ao considerar a inserção de diferentes atores e vozes, propicia menor cisão entre práticas e saberes e o desvelamento das relações de força e negociação de poder, contemplando o caráter formativo e reflexivo da experiência, que só pode ocorrer a partir de práticas cogestivas. A participação promove formas de subjetivação, transformando os participantes da pesquisa em protagonistas.

Desta pesquisa, participaram familiares, gestores, usuários e residentes de psiquiatria, sendo que, neste artigo, serão destacadas as vozes de usuários e gestores. Os critérios de inclusão dos usuários foram: ser portador de transtorno mental grave, usar medicação há mais de um ano, não ter deficiência intelectual, e possuir interesse em participar da mesma.

Para coleta de dados, foram realizados grupos de intervenção, grupos focais ${ }^{19}$ com usuários, e entrevistas com gestores de CAPS nos três centros da pesquisa: um grupo em um CAPS de Campinas; um grupo formado por usuários de Campinas com histórico de militância, realizado na Unicamp; um grupo em um CAPS em Novo Hamburgo; e um grupo em um CAPS no Rio de Janeiro. Tais serviços escolheram participar da pesquisa, a partir de convite das Universidades. 
Como garantia de sigilo, neste artigo, não serão identificados os campos, quando da retomada das vozes dos participantes da pesquisa. Foram utilizados, para análise e discussão, conteúdos de todos os campos citados anteriormente.

Os Grupos de Intervenção constituíram-se como espaços de encontro com os usuários para as discussões coletivas, a partir das experiências e de suas concepções de direitos, no contexto de leitura e reflexão do GGAM. O GGAM é uma ferramenta construída no Quebec com a finalidade de promover o protagonismo e a autonomia dos usuários na gestão dos psicofármacos, e foi adaptado e traduzido para o Brasil'. Também foi apresentada e discutida a Cartilha de Direitos dos Usuários do SUS ${ }^{20}$.

Os grupos focais (GF) foram constituídos por membros dos grupos de intervenção dos quatro campos, e contaram com um moderador, responsável por coordenar o grupo; e com um anotador, que se responsabilizou por anotar os acontecimentos e a ordem das falas dos participantes.

Os roteiros dos GF e das entrevistas abordavam diferentes temáticas relativas ao uso de medicação, tratamento, relações entre profissionais e usuários, além das concepções sobre os direitos dos usuários. Neste trabalho, utilizaremos os conteúdos ligados a esta última temática.

Os GF e entrevistas foram audiogravados e, posteriormente, transcritos e transformados em narrativas. As narrativas foram construídas por aqueles que conduziram cada grupo e/ou entrevista, e validadas, posteriormente, por outro pesquisador. Após esta etapa, as narrativas foram apresentadas aos grupos de interesse para uma validação final, o que designamos de 'grupo focal hermenêutico'1.

Para análise e interpretação dos dados, valemo-nos da abordagem hermenêutica, que se propõe a restabelecer o entendimento alterado ou inexistente, por meio da compreensão, como aponta Onocko Campos $^{21}$. Ainda, segundo a autora, quando se logra compreender, compreende-se de um modo diferente, permitindo que diferentes vozes possam compor a ressignificação das relações.

A partir da compreensão das diferentes vozes referentes aos direitos dos usuários, apostamos ser possível trazer à tona as diferentes tradições sobre essa temática e construir alguns sentidos partilhados entre os diferentes atores, promovendo permeabilidade à mudança.

\section{Direitos dos usuários: o hiato entre as diferentes percepções}

\section{Voz dos usuários}

Os usuários reconhecem como seus direitos básicos: a recusa ao tratamento, o acesso à informação e ao passe gratuito do ônibus. Atribuem importância à fonte de informações sobre direitos: se estes, muitas vezes, não são informados pelos profissionais, o fato de saberem onde procurar essas informações quando necessário traz alguma segurança.

Juntamente com o reconhecimento da informação como fonte de direitos, há uma crítica acerca da indisponibilidade de profissionais e gestores do CAPS conversarem sobre esta temática com eles.

Achamos que aqui no CAPS não há informação sobre funções dos remédios. Essas informações técnicas eles não passam para o paciente, mas de qualquer maneira, alguns de nós gostam de procurar. Teve só uma pessoa do grupo que sabia o uso. (narrativa dos usuários)

A participação na construção de Projetos Terapêuticos Singulares ${ }^{22}$ aparece como uma premissa de direito muitas vezes não respeitada, o que faz com que o Projeto seja reduzido à prescrição de atividades informadas aos usuários. A linguagem técnica usada, pelos profissionais, nos prontuários dificulta a compreensão e exclui os usuários de sua própria história.

Reconhecemos que alguns de nós não participam nem das decisões do seu projeto de tratamento, recebendo apenas informações de como deveria ser a frequência e o que deveria fazer no serviço. (narrativa dos usuários) 
É sobre o paciente ter direito de ver sua pasta, de ler seu prontuário. Um de nós já pegou para ler, mas desistiu por que não tem a chance de entender o que está escrito ali, parece inglês. (narrativa dos usuários)

\section{Voz dos gestores}

Os gestores reconhecem como direito dos usuários a universalidade do acesso e a integralidade de cuidado, além do funcionamento comunitário dos CAPS.

Lembramos da legislação que garante pelo SUS o acesso dos usuários aos CAPS, do serviço estar no território, da forma de cuidado, do atendimento integral. Mas desconhecemos legislação que diga do direito do usuário recusar a medicação. (entrevista - coordenador de CAPS)

É possível apreender que pouco diálogo há entre as leis, o conhecimento destas e as percepções do que seriam os direitos dos usuários por parte destes e dos gestores. O silêncio parece dificultar a construção de um código que dispare a circulação da palavra e real discussão sobre a possibilidade da emergência de um sujeito de direitos ${ }^{23}$.

Não podemos descartar a informação como condição básica do exercício de direitos, porém, não basta apenas informar. O sujeito de direitos é aquele que tem a experiência de direitos encarnada e é reconhecido pelo outro como tal. Nesse sentido, não é suficiente que o usuário saiba que pode, por exemplo, recusar a medicação. É também necessário que ele seja legitimado como um sujeito de direitos cuja decisão deve ser considerada pelos profissionais de saúde e comunidade.

Neste desencontro de códigos, faz-se necessária a abertura dos gestores e dos trabalhadores para a experiência do usuário. É pelo encontro da formação técnica e da função de gestão com a vivência e concepções dos usuários que a clínica e a prática do direito se articulam, criando sentido nas relações institucionais. A emergência de um sujeito de direito, que viva (ou pleiteie) esta condição nas diferentes esferas da vida, torna-se uma importante direção no cuidado em saúde mental. Se o gestor (ou trabalhador) revê sua prática e a contextualiza no encontro com o usuário, produz, para ambos, maiores graus de autonomia e de poder decisório, tornando sua ação uma práxis em saúde ${ }^{24}$.

Entendemos que a experiência de direito construída na práxis e garantida pela lei permite o reposicionamento subjetivo tanto dos trabalhadores - aí incluídos os gestores - quanto dos usuários, ampliando o trabalho de profissional de referência e sua participação nos espaços coletivos, assim como a vivência efetiva dos direitos pelos usuários.

\section{Direitos e circuito}

O estigma e o preconceito sofridos pelos usuários foram temáticas recorrentes nos achados da pesquisa. Usuários descrevem que, quando procuram o hospital geral para atendimento clínico, são reduzidos à condição de doente mental, e encaminhados ao psiquiatra. Reduz-se a demanda de cuidado a um sintoma psiquiátrico e negligencia-se a demanda de um sujeito. Nega-se a clínica ampliada ${ }^{4}$.

A questão do sujeito está esquecida e os profissionais não veem o cidadão como um todo. $\mathrm{E}$ a gente percebe isso, porque um de nós teve agora um problema de saúde que é sério, foi ao hospital e eles falaram que era um problema da saúde mental. Mas como é que é de saúde mental, se tá saindo sangue no xixi, neste caso? (narrativa dos usuários)

O direito ao benefício e o direito ao trabalho aparecem, frequentemente, em uma relação excludente que caracteriza o estigma, já que a vivência é a de que um direito exclui o outro. Se o usuário tem direito ao benefício financeiro por adoecimento, receber um diagnóstico psiquiátrico dificulta o retorno ao mercado profissional. 
Em relação ao trabalho temos grande impotência. Se é aposentado não tem direito a emprego. Se vai trabalhar não consegue. Se falar que faz tratamento, ninguém dá emprego, que toma remédio é repugnado [...], aposentadoria parece apagar nossa possibilidade de trabalhar, embora alguns de nós reconhece ... reconheça a necessidade de estar trabalhando se não tivéssemos fazendo tratamento. (narrativa dos usuários)

Verifica-se que, na prática cotidiana, para ter acesso à medicação psiquiátrica de alto custo em alguns estados, o usuário deve ser diagnosticado com esquizofrenia, mesmo que este não seja o seu diagnóstico. A condição para receber o remédio é possuir o diagnóstico que o rotula como portador de uma doença passível de preconceitos, mesmo que não a tenha.

Numa das cidades em que a pesquisa foi realizada, para receber o passe de ônibus gratuito, quase sempre é necessário protocolar a esquizofrenia do usuário, mesmo que este não seja o diagnóstico. Recebe o passe gratuito, e junto com ele a perpetuação do estigma.

É possível apreender o funcionamento de um circuito mantenedor da situação de vulnerabilidade dos usuários dos serviços de saúde mental: o usuário tem acesso a direitos sociais devido ao adoecimento, e tal acesso o estigmatiza, inviabilizando-o como sujeito de direitos. Este circuito é reforçado ao não serem construídas, com o usuário, formas de sair deste lugar, passando a ser, cada vez mais, dependente das decisões externas.

Deste circuito participam gestores e profissionais, que reforçam as práticas e diagnósticos, mesmo que com eles não concordem; e usuários, que podem ocupar estes lugares para acessar condições mínimas de tratamento e de vida, frente às incertezas de uma sociedade organizada pela lógica do Estado mínimo.

\section{Sobre direitos e práticas totais}

Oliveira e Passos $^{7}$ chamam a atenção para as formas de controle a céu aberto que a loucura pode ter a partir do enfraquecimento ou dissolução das instituições disciplinares. A série doença mentaltutela-manicômio, embasada na tutela dos corpos no sistema hospitalocêntrico, pode ser substituída pela série doença mental-controle-serviços abertos.

Por parte de alguns gestores, aparece a preocupação em filtrar os direitos dos usuários, evitando informações acerca do direito à recusa da medicação e de outras formas de tratamento.

Eu não acho bom quando a gente toma essa questão pela via do direito [referindo-se ao direito do usuário poder recusar qualquer procedimento, inclusive a medicação]. Está escrito na lei que ele pode recusar, vou dar um papel pra ele, pra ele ficar bem informado a respeito disso. Acho isso meio fora do contexto, não está nas discussões cotidianas aqui do CAPS, é complicado. (entrevista - coordenadora de CAPS)

A lógica do controle se expressa com o uso de "filtros de proteção" que mantêm o silenciamento sobre as formas de gestão do tratamento ou do equipamento de saúde. A este respeito, ouvem-se as críticas dos usuários:

Enfermeiro, psicólogo, psiquiatra, coordenador. Então tem um tipo de hierarquia aqui dentro. Então, o que acontece? Você reclama para o referência, a referência às vezes esquece, [...] não vai lá no doutor tal e fala: o meu paciente que está comigo está precisando disso, disso e disso. Então, o que eles fazem? Eles não sintonizam bem, entendeu? (narrativa de usuários)

O CAPS pode acabar por assumir o lugar do controle, quando define o que é permitido ao usuário saber ou questionar. Promove-se tanto infantilização do usuário quanto o seu outro extremo: o usuário que tudo pode, sem corresponsabilizar-se por nada. Nos dois extremos, assume-se o mandato social de responder pelo sujeito 
Ou a gente pode pensar que todos os pacientes, inclusive psicóticos graves, estão no campo da razão e, assim, podem escolher, e... então, eles vão ser presos, porque é a única consequência que eu posso imaginar. (entrevista - coordenadora de CAPS)

Cabe à gente, somos nós do campo da saúde mental, que temos um mandato social de definir que naquela hora quem manda sou eu. Quem diz se vai ter que ser internado, por exemplo, ou se vai ter que tomar uma medicação sou eu, porque acho que é disso que aquele paciente precisa naquele momento, porque senão ele vai fazer uma besteira com ele ou com alguém. E eu acho que a gente ainda funciona muito nesse princípio. (entrevista - coordenadora de CAPS)

A discussão sobre medicação com os usuários parece ser um emblema do que vimos conversando até agora. O uso de medicação, a falta de discussão e o pouco poder decisório do usuário na negociação parecem representar uma espécie de caixa preta da Reforma Psiquiátrica Brasileira. Num dos campos da pesquisa, há desligamento do usuário caso ele negue-se a tomar remédio.

Mas quando a pessoa está bem, com juízo crítico preservado e se recusa a tomar a medicação, ainda estamos avaliando, porque até pouco tempo a conduta era: se tem a indicação e tem crítica, segue com a indicação de tomar a medicação; mas, se a pessoa não está aderindo ao tratamento e não está seguindo as orientações, a equipe não sente que está tratando aquela pessoa. Então, na recusa a tomar a medicação, muitos profissionais têm a conduta de assinar no prontuário e desligar o usuário de todo o tratamento. (entrevista - coordenadora de CAPS)

Neste caso, a equipe passa a adotar a mesma perspectiva unilateral do usuário que sozinho decide parar de tomar a medicação, e entende que a escolha pauta-se apenas pela racionalidade, transformando uma possível piora decorrente da suspensão de medicação em culpabilização do sujeito.

Esta gestora discorda da prática e procura modos de lidar com a situação. Porém, na funçãogestão, não seria necessário ratificar o compromisso do CAPS em construir outras formas de manejo, objetivando a geração, entre equipe e usuários, de ações que visem maiores graus de autonomia e corresponsabilização? Não seria necessário discutir com a equipe formas de cuidar do usuário para além da obrigatoriedade do uso da medicação?

A função gestão em equipamentos substitutivos tem por premissa fugir da racionalidade gerencial hegemônica ${ }^{25}$, transitando entre o gerir e o gerar ${ }^{26}$. Para isto faz-se necessário que estratégias coletivas sejam construídas na organização e modulação de relações cotidianas nos serviços. Isto é um exercício político, de desnaturalização de práticas e de questionamento de poderes.

Há o reconhecimento do desafio:

É um aprendizado também pra gente enquanto cuidador [...] se a gente estivesse num hospital, com certeza a gente não estaria pensando sobre isso aqui (direitos) [...] são coisas que até fora do trabalho são questões que a gente também não consegue muito lidar, com a liberdade, com o direito de cada um, isso na sociedade é muito difícil, então aqui dentro não é muito diferente, só que a diferença é que aqui a gente tá no lugar de cuidador. (entrevista - coordenadora de (APS)

Em outra fala, outro coordenador de CAPS alerta:

Então, por um lado, é muito importante que seja preservado esse direito (de informação sobre a recusa da medicação) mas, eu acho que isso dá só mais trabalho pra gente.

Fica-nos uma pergunta: quem dá o direito a outrem de ocultar o que lhe é constitucionalmente garantido?

De forma mais velada, numa instituição aberta, o ranço de práticas que desprezam a singularidade do sujeito e a capacidade de protagonismo e de construções pactuadas pode permanecer. 
Se não mais se aprisionam pessoas em instituições totais, pode-se operar por práticas totais que tendem a, cotidianamente, ressuscitar a ausência política dos usuários. Tais práticas desconsideram o exercício dos papéis sociais vivenciados pelos usuários, deslegitimando diferentes formas de subjetivação. Práticas totais, enfim, que silenciam ou fecham-se à palavra do usuário, que desconsideram sua fala como acesso à realidade de seu mundo. Liberta-se o sujeito do asilo, mas não da normalização dos processos de vida e da universalização de formas de sentir, agir e pensar.

Não informar o usuário sobre seus direitos e não trabalhar com ele, tais questões são práticas totais. Desligar o usuário por recusa ao uso da medicação também.

Se as instituições totais são, por definição, instituições disciplinares que consideram o corpo como realidade a ser vigiada e modelada, as práticas totais podem modular de um diagrama do poder disciplinar para um do biopoder, ao buscar disciplinar os corpos e regulamentar os processos de vida, "funcionando de forma capilar nas instituições sociais, diluindo-se por todo o tecido social"7 (p. 324). Mesma lógica, espaços diferentes. A série doença mental-controle-serviços abertos se solidifica.

Apostamos que o direito deve ser informado e que seu exercício deve ser compartilhado com o usuário na perspectiva de aumentar graus de autonomia e de corresponsabilização, considerando-o como sujeito da experiência ${ }^{27}$ : experiência válida como a nossa, mesmo que diferente.

Para que tais estratégias possam ser adotadas, faz-se necessário que a equipe e gestores estejam constantemente em análise. O risco de assumir práticas totais travestidas de libertárias constantemente atravessa os equipamentos de saúde a céu aberto.

Oliveira e Passos ${ }^{7}$ apontam para o risco de novas cronicidades decorrentes da modulação pelo biopoder: cronicidade dos usuários que são retidos nos muros invisíveis dos CAPS;

cronicidade dos efeitos dos dispositivos de saúde mental, efeito da inexistência ou fragilidade da rede de atenção em saúde que não amplia nem conecta os diferentes serviços, garantindo uma efetiva abertura dos CAPS que tendem a possuir 'porta de entrada', mas muitas vezes, não possuem 'porta de saída'? (p. 336)

Há, também, a cronicidade dos profissionais, que não podem deixar de colocar em análise os modos de atenção e gestão, assim como os equipamentos de saúde em que trabalham ${ }^{28}$.

Complementamos a ideia dos autores com a cronicidade dos gestores, que podem fugir ao exercício de sua função. Por exemplo, quando escolhem o que informar aos usuários, visto que isto pode "dar trabalho" à equipe; ou quando não se posicionam frente à equipe sobre a necessidade de prerrogativas básicas do SUS serem sustentadas.

\section{Considerações finais}

Durante o percurso de compreensão dos dados, percebemos que a problematização do direito disparou ecos num silêncio mais profundo. Além do acesso à informação, também se mostrou necessário compreender o que era feito com ela.

$\mathrm{Na}$ compreensão das narrativas dos usuários e dos gestores, pudemos apreender que o silenciamento sobre os direitos aumenta a concentração de poder dos gestores e equipamentos, aumentando a violência simbólica.

Pudemos interpretar, também, a formação de um circuito a partir da ausência dos direitos, ou da impossibilidade de exercício destes. Tais circuitos legitimam-se num país em que o acesso a direitos sociais básicos é precário para grande parcela da população, sendo que, em alguns momentos, a inscrição neste círculo, se, por um lado estigmatiza, por outro, torna a sobrevivência possível.

Nas repetições geradas por tal circuito, uma delicada questão salta: a consecução de benefícios especiais pode enfraquecer a luta contra o estigma e busca por direitos civis comuns a todos cidadãos, visto que poderia haver um reforço da competência técnica e da mediação de serviços de saúde para isto 9 .

Novos tipos de cronificação podem ser vividos, como a dos usuários, dos profissionais, dos serviços e dos gestores. 
O fechamento dos hospícios não soluciona a questão dos direitos dos usuários, por mais que seja o primeiro ponto a ser sacramentado. O exercício do direito por parte dos usuários é aprisionado pela instituição loucura ao longo dos séculos.

A emergência de sujeitos de direitos não pode se dar senão no plano coletivo, por um lado, como prática vivida de intersubjetividade (pactuação, produção de regras) e, por outro, a partir da gestão coletiva e compartilhada do cuidado, que geste modos de existência mais livres, com incorporação efetiva da autonomia dos usuários e dos direitos humanos.

Neste sentido, a emergência do sujeito de direitos aproxima-se de uma práxis em saúde que pode ter o CAPS como meio para o usufruto do direito do usuário, articulador de redes, promotor de processos de subjetivação que possam ser potencializados em outros encontros.

Torna-se fundamental que a temática dos direitos seja retomada e problematizada pela Reforma Psiquiátrica Brasileira, sob o risco de este catalisador e alicerce de seu movimento tornar-se apenas retórica, presente nos textos e discursos, vazio de sentido na vida dos usuários. Pensar a democracia psíquica ${ }^{29}$ extrapola o campo da saúde mental, comprometendo-nos com a construção de uma democracia social.

Que os sujeitos, loucos ou não, possam construir coletivamente formas de resistir ao esquecimento dos direitos humanos. E que a universalidade de acesso não seja pensada apenas a partir das portas concretas abertas mediante portarias legais, mas que, também, considere os interstícios que aquecem as relações de poder e silenciam sujeitos.

\section{Colaboradores}

Os autores trabalharam juntos em todas as etapas de produção do manuscrito.

\section{Referências}

1. Onocko Campos $R$, Palombini AL, Silva AE, Passos E, Leal EM, Serpa Junior OD, et al. Adaptação multicêntrica do guia para a gestão autônoma da medicação. Interface (Botucatu). 2012; 16(43):967-80.

2. Ministério da Saúde. Secretaria de Atenção à Saúde. Departamento de Ações Programáticas Estratégicas. Saúde mental no SUS: os centros de atenção psicossocial. Brasília (DF): MS; 2004.

3. Goffman E. Manicômios, prisões e conventos. São Paulo: Perspectiva; 1974.

4. Campos GWS, organizador. Saúde Paidéia. São Paulo: Hucitec; 2003.

5. Amarante P. Saúde Mental e atenção psicossocial. Rio de Janeiro: Fiocruz; 2007.

6. Onocko Campos R, Campos GWS. Co-construção de autonomia: o sujeito em questão. In: Campos GWS, Minayo MCS, Akerman M, Drumond Junior M, Carvalho YM, organizadores. Tratado de saúde coletiva. São Paulo: Hucitec; 2006. p. 669-88.

7. Oliveira JAM, Passos E. Novos perigos pós-desospitalização: controle a céu aberto nas práticas de atenção à saúde mental. In: Carvalho $S R$, Ferigato $S$, Barros $M E$, organizadores. Conexões: saúde coletiva e políticas da subjetividade. São Paulo: Aderaldo \& Rothschild; 2009. p. 322-41.

8. Lei $n^{\circ} 10216$, de 6 de abril de 2001. Dispõe sobre a proteção e os direitos das pessoas portadoras de transtornos mentais e redireciona o modelo assistencial em saúde mental. Diário Oficial de União. 6 Abr 2001. 
9. Vasconcelos EM. O poder que brota da dor e da opressão: empowerment, sua história, teorias e estratégias. São Paulo: Paulus; 2003.

10. Onocko Campos R, Furtado JP, Miranda L, Ferrer AL, Passos E, Gama CAP. Avaliação da rede de centros de atenção psicossocial: entre a saúde coletiva e a saúde mental. Rev Saude Publica. 2009; 43(1):16-22.

11. Freitas C. A participação e preparação prévia do usuário para situações de crise mental: a experiência holandesa do plano/cartão de crise e desafios para sua apropriação no contexto brasileiro. In: Vasconcelos EM, organizador. Abordagens psicossociais: Reforma Psiquiátrica e Saúde Mental na ótica da cultura e das lutas populares. São Paulo: Hucitec; 2008. v. 2, p. 142-70.

12. Presotto RF. Participação de usuários de serviços de Saúde Mental em pesquisas: um olhar a partir dos conceitos de empowerment e recovery [dissertação]. Campinas (SP): Faculdade de Ciências Médicas, Universidade Estadual de Campinas; 2013.

13. Ludmila CC. Guia de direitos humanos loucura cidadã. Salvador: AMEA; 2011.

14. Yasui S. Rupturas e encontros: desafios da reforma psiquiátrica brasileira. Rio de Janeiro: Fiocruz; 2010.

15. Passos E, Otanari TMC, Emerich BF, Guerini L. O Comitê Cidadão como estratégia cogestiva em uma pesquisa participativa no campo da saúde mental. Cienc Saude Colet. 2013; 18(10): 2919-28.

16. Minayo MCS. A utilização do método qualitativo para a avaliação de programas de saúde. In: Onocko Campos R, Furtado JP, Passos E, Benevides R, organizadores. Pesquisa avaliativa em saúde mental: desenho participativo e efeitos da narratividade. São Paulo: Aderaldo \& Rothschild; 2008. p. 27-37.

17. Furtado JP, Onocko Campos R. Participação, produção de conhecimento e pesquisa avaliativa: a inserção de diferentes atores em uma investigação em saúde mental. Cad Saude Publica. 2008; 24(11):2671-80.

18. Guba EG, Lincoln YS. Fourth generation evaluation. Newbury Park: Sage Publications; 1989.

19. Miranda L, Figueiredo MD, Ferrer AL, Onocko Campos R. Dos grupos focais aos grupos focais narrativos: uma descoberta no caminho da pesquisa. In: Onocko Campos $\mathrm{R}$, Furtado JP, Passos E, Benevides R, organizadores. Pesquisa avaliativa em saúde mental: desenho participativo e efeitos da narratividade. São Paulo: Aderaldo \& Rothschild; 2008. p. 249-77.

20. Ministério da Saúde. Carta dos direitos dos usuários da saúde. Brasília (DF): MS, 2006.

21. Onocko Campos R. Metodologia de pesquisa em políticas de planejamento e gestão em Saúde Coletiva. In: Barros NF, Cecatti JG, Turato ER, organizadores. Pesquisa qualitativa em saúde: múltiplos olhares. Campinas: Unicamp; 2005. p. 261-71.

22. Oliveira GN. O Projeto Terapêutico Singular. In: Campos GWS, Guerrero AVP, organizadores. Manual de práticas na atenção básica: saúde ampliada e compartilhada. São Paulo: Aderaldo \& Rothschild; 2008. p. 283-97.

23. Passos E, Silva AE. Autonomia e direitos humanos na experiência em primeira pessoa de técnicos e usuários em serviço de saúde mental: a experiência da gestão autônoma da medicação (GAM) [relatório final FAPERJ Programa APQ1 2009/1]. Rio de Janeiro; 2011.

24. Campos GWS. Cogestão e neoartesanato: elementos conceituais para repensar o trabalho em saúde combinando responsabilidade e autonomia. Cienc Saude Colet. 2010; 15(5): 2337-44.

25. Campos GWS. Um método para a análise e co-gestão de coletivos: a constituição do sujeito, a produção do valor de uso e a democracia em instituições: o método da roda. São Paulo: Hucitec; 2000. 
26. Onocko Campos R. A gestão: espaço de intervenção, análise e especificidades técnicas. In: Campos GWS, organizador. Saúde Paidéia. São Paulo: Hucitec; 2003. p. 122-49.

27. Bondia JL. Notas sobre a experiência e o saber de experiência. Rev Bras Educ. 2002; (19):20-8.

28. Oliveira JAM, Passos E. A implicação de serviços de saúde mental no processo de desinstitucionalização da loucura em Sergipe. Vivência (Natal). 2007; 1:259-275.

29. Lancetti A. Clínica peripatética. São Paulo: Hucitec; 2011.

Emerich BF, Campos RO, Passos E. Derechos en la locura: lo que dicen los usuarios y gestores de los Centros de Atención Psicosocial (CAPS). Interface (Botucatu). 2014; 18(51):685-96.

Por medio de la problematización del concepto de autonomía y de la interfaz con el ejercicio de derechos, pretendese identificar y comprender la concepción de derechos de los usuarios de CAPS, a partir de sus voces y de los gestores de estos servicios. Se trata de un estudio multi-céntrico cualitativo de cuarta generación, cuyo material se obtuvo en grupos focales y entrevistas que se grabaron en audio. La comprensión de los datos indica que el ejercicio de los derechos se hace posible por la emergencia de sujetos de derechos. Analizando las relaciones entre estos actores, moduladas por el biopoder, fue posible captar la formación de un circuito en el que los usuarios se insieren. A cielo abierto, las prácticas totales producen formas de control sobre usuarios y el ejercicio de derechos, lo que puede generar cronicidad de los usuarios, trabajadores, servicios y gestores.

Palabras clave: Salud mental. Autonomía. Derechos humanos. Psiquiatría. Estudio cualitativo.

Recebido em 26/12/13. Aprovado em 21/07/14. 


\section{Errata}

Esta errata refere-se apenas ao número das citações indicadas no texto a partir da página 687.

p. 687 , onde se lê

Lei $10216^{10}$ e a "Carta de direitos e deveres dos usuários e familiares dos serviços de saúde mental" 11 .

Onocko Campos et al. ${ }^{13}$

O Cartão e Plano de Crise ${ }^{14}$

o correto é:

Lei $10216^{8}$ e a "Carta de direitos e deveres dos usuários e familiares dos serviços de saúde mental"9.

Onocko Campos et al. ${ }^{10}$

O Cartão e Plano de Crise ${ }^{11}$

p. 688 , onde se lê:

dispositivos grupais ${ }^{15}$

Ambulante ${ }^{16}$.

Psiquiátrica ${ }^{17}$.

medicamentoso ${ }^{19}$.

socialmente ${ }^{21}$.

geração ${ }^{22}$ propicia a inclusão de diferentes pontos de vista e valores dos grupos de interesse envolvidos ${ }^{23}$.

grupos focais ${ }^{24}$

o correto é:

dispositivos grupais ${ }^{12}$.

Ambulante ${ }^{13}$.

Psiquiátrica ${ }^{14}$.

medicamentoso $0^{15}$.

socialmente ${ }^{16}$.

geração ${ }^{17}$ propicia a inclusão de diferentes pontos de vista e valores dos grupos de interesse envolvidos ${ }^{18}$.

grupos focais $^{19}$ 
p. 689 , onde se lê:

Usuários do SUS26.

Onocko Campos ${ }^{28}$.

Projetos Terapêuticos Singulares ${ }^{29}$

o correto é:

Usuários do SUS20.

Onocko Campos ${ }^{21}$.

Projetos Terapêuticos Singulares ${ }^{22}$

p. 690 , onde se lê:

sujeito de direitos ${ }^{30}$.

práxis em saúde ${ }^{31}$.

o correto é:

sujeito de direitos ${ }^{23}$.

práxis em saúde ${ }^{24}$.

p. 692 , onde se lê:

racionalidade gerencial hegemônica ${ }^{34}$, transitando entre o gerir e o gerar ${ }^{35}$.

o correto é:

racionalidade gerencial hegemônica ${ }^{25}$, transitando entre o gerir e o gerar ${ }^{26}$.

p. 693 , onde se lê:

sujeito da experiência ${ }^{37}$

trabalham ${ }^{39}$.

o correto é:

sujeito da experiência ${ }^{27}$

trabalham ${ }^{28}$.

p. 694 , onde se lê:

Pensar a democracia psíquica ${ }^{41}$

o correto é:

Pensar a democracia psíquica ${ }^{29}$ 